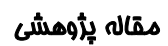

\section{بررسى ميزان آكاهى و عملكرد مادران شهر مشهد در مورد تغذيه انحصارى با شير مادر در 9 ماهه اول زندكى كودى}

\author{
محمد على كيانى '، على خاكشور '، رحيمر وكيلى '، معصومه سعيدى '"* \\ 'استاديار، فوق تخصص كوارش اطفال، مركز تحقيقات نوزادان، دانشكده يزشكى، دانشكاه علوم يزشكى مشهد، مشهد، ايران

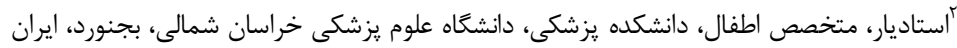

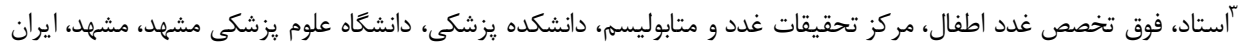

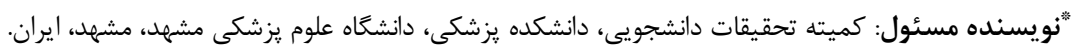 \\ يست الكترونيك:Masumeh_Saeedi@yahoo.com
}

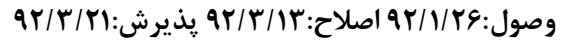

جكيده

زمينه و هدف: تغذيه با شيرمادر يكى از اصول مههم در تامين سلامتى شيرخواران مى باشد. تغذيه انحصارى با شيرمادر در ع ماهه اول

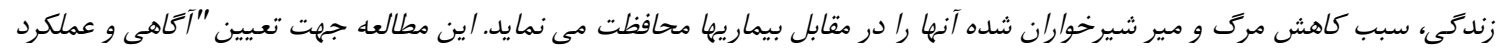

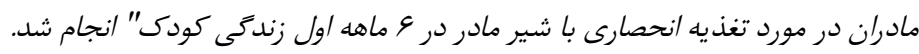

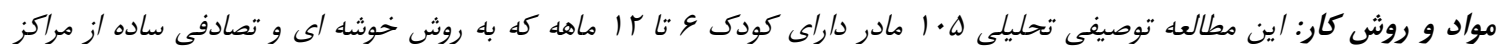

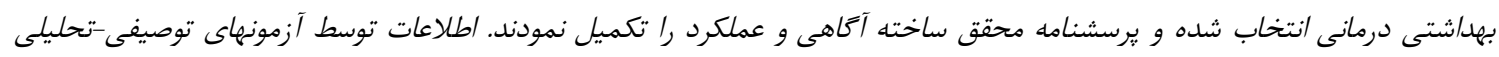

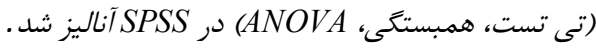

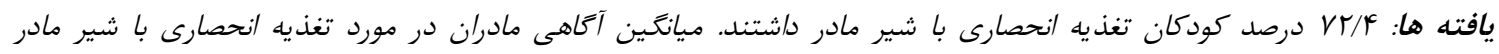

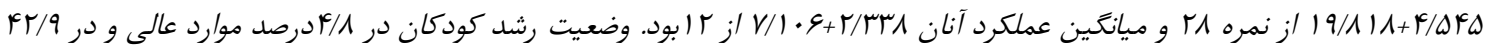

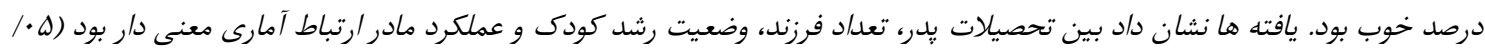

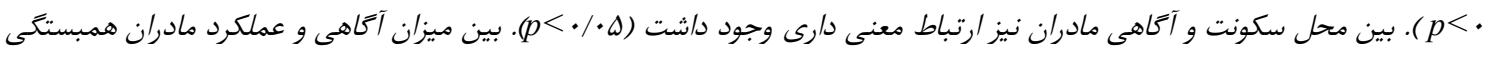

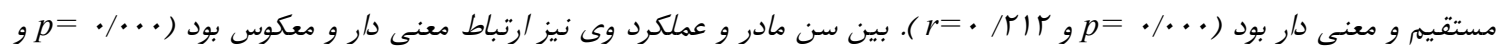
$(r=\cdot / r) T$

نتيجه تَيرى: آكاهى و عملكرد مادران نسبت به تغذيه انحصارى كودى با شير مادر در حد متوسط مى باشد. ضروريست برنامه ريزى

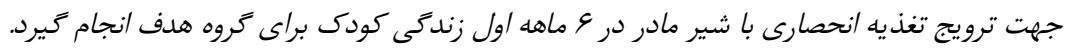
واثه هاى كليدى: آكاهى - عملكرد - تغذيه انحصارى - شيرخوار

إيدميولوزيك اثر شير انسان را در كاهش مرى و مير مقدمه

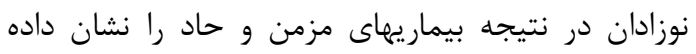
شير مادر يكى از سالمترين روشهاى تغذيه كودك است و

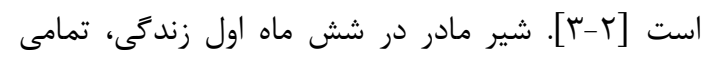

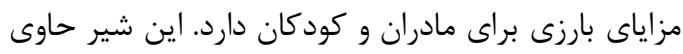

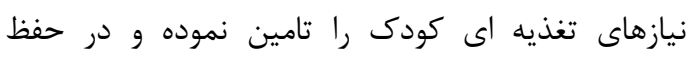

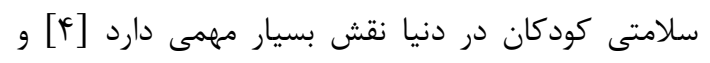
عناصر مغذى است كه حداقل تا سن شش ماهكى بهترين تعادل تغذيه اى را براى كودى فراهم ميكند. تغذيه با شير شروع تغذيه تكميلى مى تواند بر رشد شيرخوار، تاثير

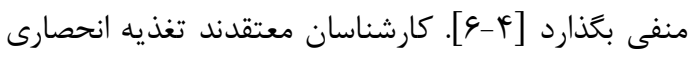

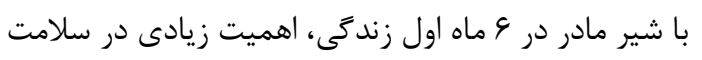
مادر باعث كاهش خطر بيماريه اي عفو نى، ديابت، سرطان، آسم و جاقى كودكان مى شود و علاوه بر آن شيردهى مزاياى اقتصادى نيز در بردارد [1] إن. مطالعات 
كودى خويش را تا وماهكى به طور انحصارى با شيرخود

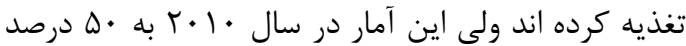

$$
\text { رسيده است [rD،rV] }
$$

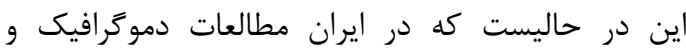

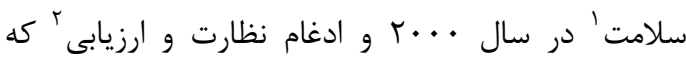

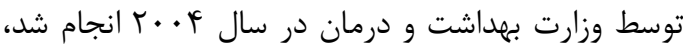

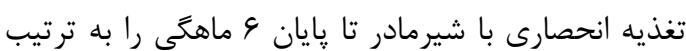
FF در مطالعات مختلف نتايج ضد و نقيضى در ارتباط با عوامل

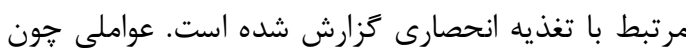
جنس شيرخوار، سن، سواد، شغل و ياريتى مادر، آموزش هاى قبل از زايمان و زمان شروع شيردهى در بعد از

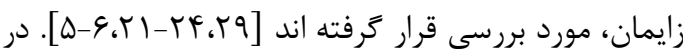
مطالعاتى نيز بين جنس شيرخوار و تغذيه انحصارى ارتباط بروسي معنادار، وجود نداشته است [ع-ه]]. در سالهاى اخير تلاش بسيارى در جهت ترويج تغذيه انحصارى در سيستم شبكه بهداشتى-درمانى كشور انجام گرفته است. با توجه به اهميت ارتقاء و ترويج تغذيه انحصارى با شير مادر و تعيين

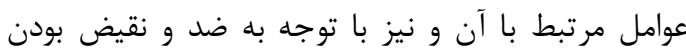

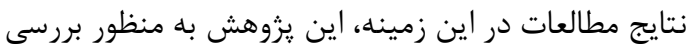
آكاهى وعملكرد مادران شهر مشهر در مورد تغذيه انحصارى با شير مادر در 4 ماهه اول زندگى كودى انجام

اين مطالعه توصيفى تحليلى از نوع مقطعى مى باشد. جامعه يزوهش در اين مطالعه مادران داراى شيرخوار Tا ماهه مراجعه كننده به مراكز بهداشتى درمانى مشهرد جهت يايش رشد كودى و حجم نمونه يزوهش با روش خوشه اى و تصادفى ساده انتخاب زرديد كه با خطاى ه••

$$
\text { درصد، ه • ا نفر تعيين شد. }
$$

روش نمونه گيرى به اين صورت بود كه كل شهر مشهد به

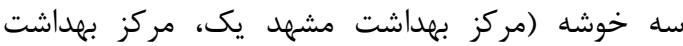

\section{1 -DHS( Demoghraphic and Health Surveys)}

2 -IMES(Integrated Monitoring and Evaluation System)
و كاهش مرى و مير كودكان داشته [V-ᄉ] و علاوه بر كاهش مرگ و مير نوزادى مى تواند از بسيارى از بيمارى هاى دوران كودكى ييشخيرى كند [11-9]. شير مادر به مريه دليل دارا بودن بسيارى از مواد شناخته شده و ناشناخته، به خصوص اسيدهاى جرب ضرورى براى رشد مغز و تكامل اعصاب، اهميتى ويره دارد [IT] جهانى بر ادامه تغذيه انحصارى در ع ماه اول زندكى تاكيد

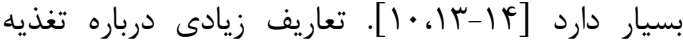
نحصارى با شير مادر در منابع علمى آورده شده است ولى لى لهي تعريفى كه بيشتر استفاده مى شود عبارت است ازي إن "تغذيه نوزاد با شيرمادر به تنهايى بدون تغذيه با ساير مواد غذايى و حتى آب كه اين مواد شامل داروها، واكسن ها، ويتامين

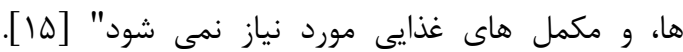

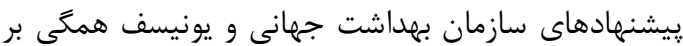
تغذيه انحصارى با شيرمادر در \& ماه اول زندگى و شروع تغذيه كمكى از پايان ماه \& تا اسالكى تاكيد دارند [19. از طرفى نياز به ارتقا و حمايت شيردهى جهت سلامتى و وان ماه تكامل كودكان امرى غيرقابل انكار بوده و تغذيه با شير

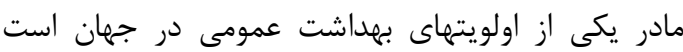
. [IV]

در بررسى هاى به عمل آمده توسط دست اندر كاران ترويج

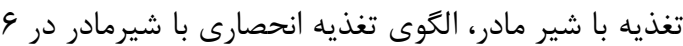
ماه اول زندگى در نقاط مختلف جهان متفاوت است. در ماري

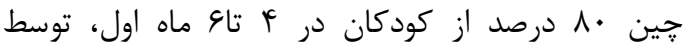
شيرمادر به صورت انحصارى تغذيه مى شوند [11]]. به دونه

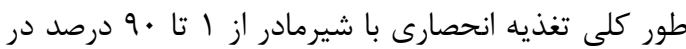
نقاط مختلف جهان متفاوت است [19]. شيوع تغذيه

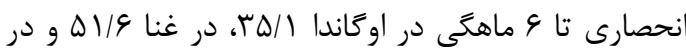

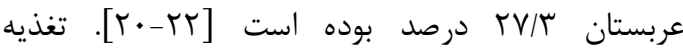

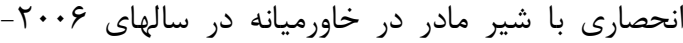

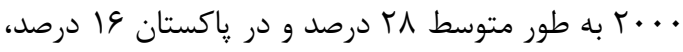

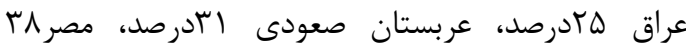
درصد و در ايران FF درصد ززارش شده است [rr] عوامل اقتصادى ـاجتماعى، دموگرافيك، فرهنگىى، مامايى و نوزادى در توقف زودهنگام تغذيه انحصارى موثر شناخته شده است. اين عوامل در جوامع مختلف متفاوت مى باشد

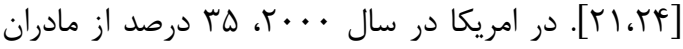


نسبت به تغذيه انحصارى با شيرمادر بود (هم اتاقى بودن يس از تولد نوزاد، تعداد دفعات شير دادن، مواقع شير

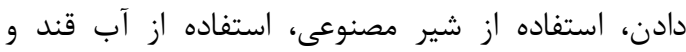

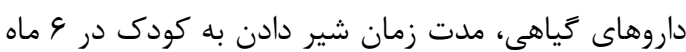

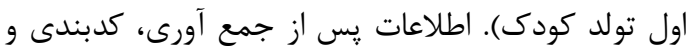

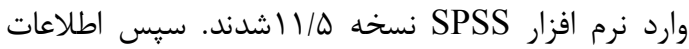
كدبندى شده با آزمونهاى توصيفى (ميانخين -جدول توزيع

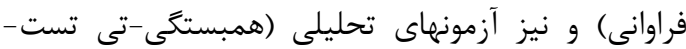
(ANOVA مورد تجزيه و تحليل قرار گرفتند.

يافته ها

ميانگين سن مادران

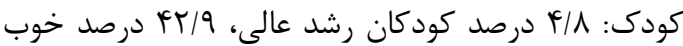

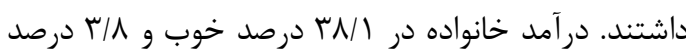

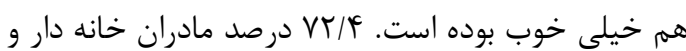

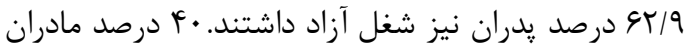

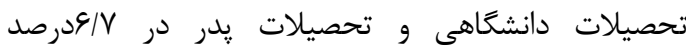

ابتدايى و له/ه ب درصد راهنمايى بوده است (جدول ()). ميانگين آكاهى مادران در مورد تغذيه انحصارى با شير

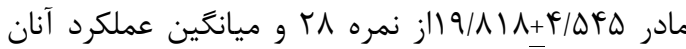
אسr/r/ M/A درصد مادران بعد از تولد كودك با وى هم اتاق بوده

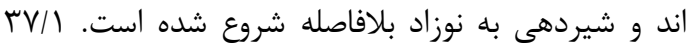

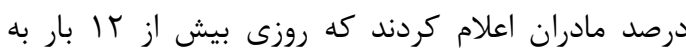
كودك خود شير داده و شيردهى به كودك در بقيه موارد كمتر از اين مقدار بوده است. يافته ها نشان داد

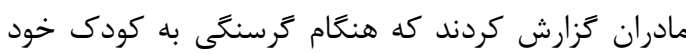
شير داده و بقيه مادران ساعات مشخصى از شبانه روز ران إن

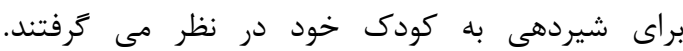
شيردهى اختصاصى به كودك در 9 ماهه اول تولد فقط در

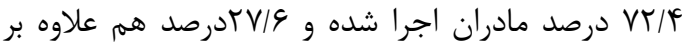
شير مادر مواد ديخرى نيز به كودى مى دادند. ماند يافته ها

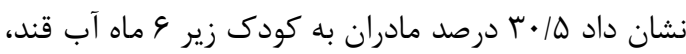

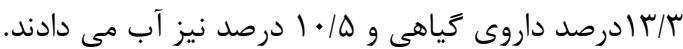
يافته ها نشان داد F و درصد مادران در مورد نشانه هاى

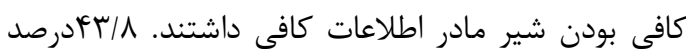
مادران بيان كردند كه براى تغذيه كودى شيرخوار كمتر از ماردي 9 ماه علاوه بر شير مادر، كودى نياز به مايعات ديگرى هم
مشهد دو و مركز بهداشت مشهد سه) تقسيم و در هر خوشه به روش تصادفى ساده r مراكز بهداشتى درمانى

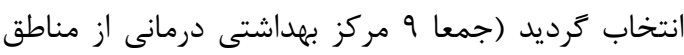

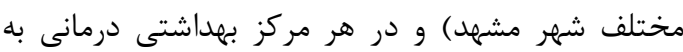
روش تصادفى ساده نمونه مورد نظر انتخاب گرديد، به اين صورت كه يزوهشگران با هماهنگى با مسوول مراكز بهداشتى درمانى به كلينيك مادر و كودك در هر مركز بهداشتى درمانى مراجعه نموده و با انتخاب مادر (داراى كودى ع تا با ماهد، مليت ايرانى، داشتن فرزند زنده دماند بدون ناهنجارى شناخته شده، داشتن پرونده در مركز بهداشتى درمانى، نداشتن سابقه هيج گونه بيمارى جسمى، روانى و اعتياد به سيخار، الكل و مواد مخدر طبق لمقيق

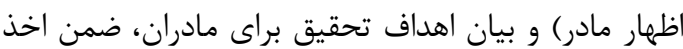

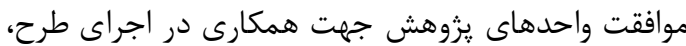

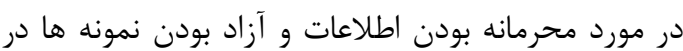
رد يا قبول شركت در يزوهش نيز توضيحاتى ارائه و در در بونه صورت رضايت مادران، يرسشنامه تحقيق در اختيار آنان قرار گرفته و در صورتى كه مادر سواد كافى نداشت از رهائ

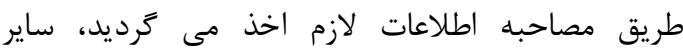
اطلاعات مربوط به رشد كودى از يرونده كودى استخراج كرديد.

روش گردآورى اطلاعات بر اساس يرسشنامه ایى يزوهشگر ساخت بود كه روايى آن توسط صاحبنظران و پايايى آن (توسط آزمون آمارى) تاييد شده بود، به اين صورت كه بوديط روايى يرسشنامه با استفاده از كتب، دستورالعمل ها و وإن

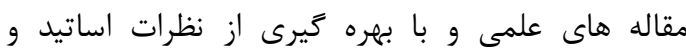
كارشناسان دست اندركار تعيين شد. براى تعيين رِايايى آن نيز از روش ثبات درونى (ضريب آلفاى كرونباخ)

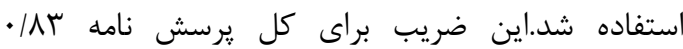

محاسبه شد.

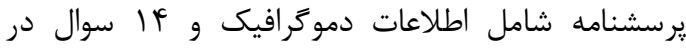
خصوص آتاهى مادر در مورد تغذيه انحصارى كودى با ليامل شير مادر (فوايد تغذيه با شير مادر، مضرات عدم شيردهى به موقع براى شيرخوار، مدت تغذيه انحصارى با شير مادر، تغذيه با شير مادر و نقش آن در ايمنى شيرخي خوار، مدت مدات زمان مكيدن يستان مادر، نياز به مابعات هنعام تغذيه انحصارى شيرخوار) و و سوال در مورد عملكرد مادران 


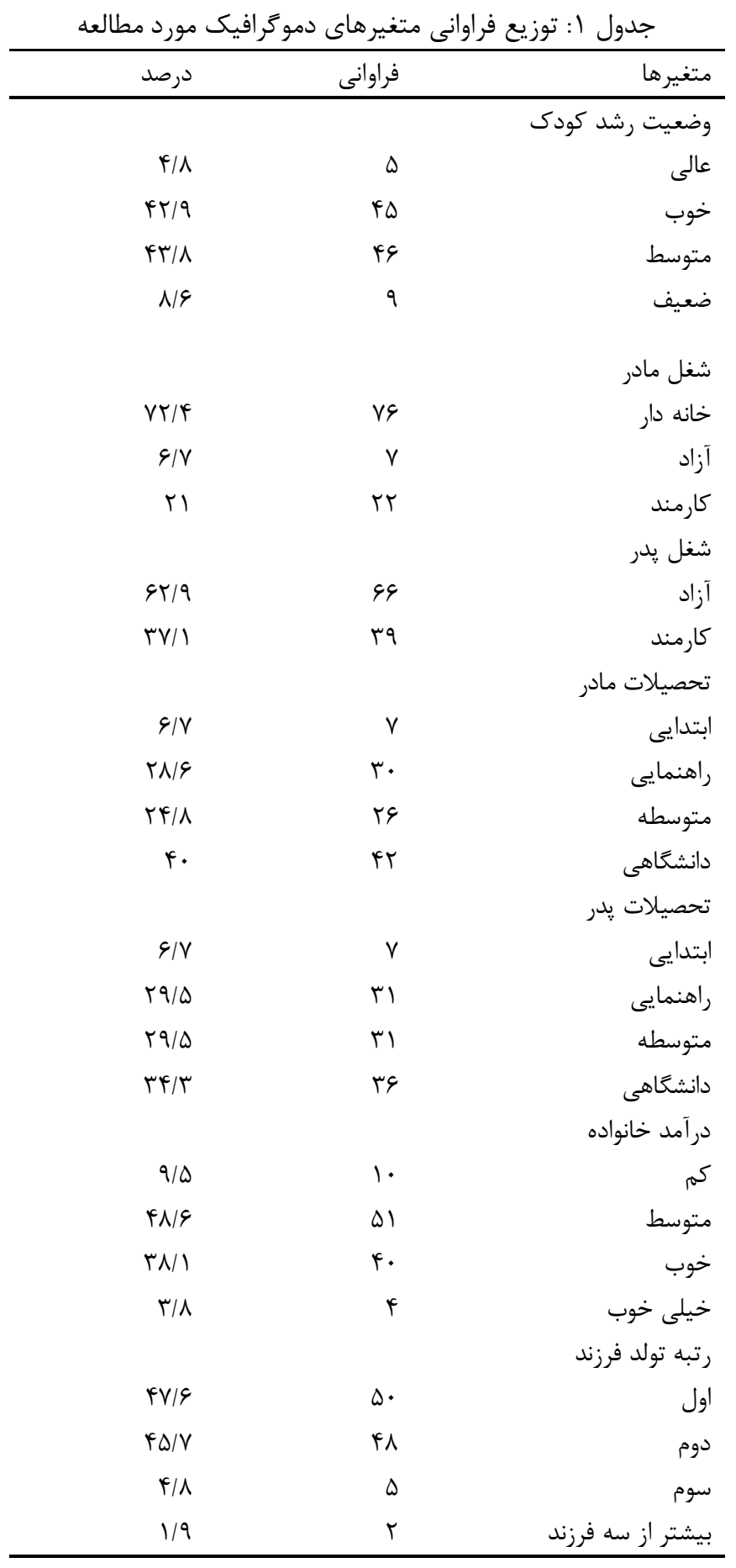

\begin{tabular}{|c|c|c|c|}
\hline نمره كل & انحراف معيار & ميانكين & متغير \\
\hline$r \Lambda$ & $F / \Delta F \Delta$ & $19 / 111$ & آكاهى \\
\hline ir & ג ג & $V / 1 \cdot 9$ & عملكرد \\
\hline
\end{tabular}




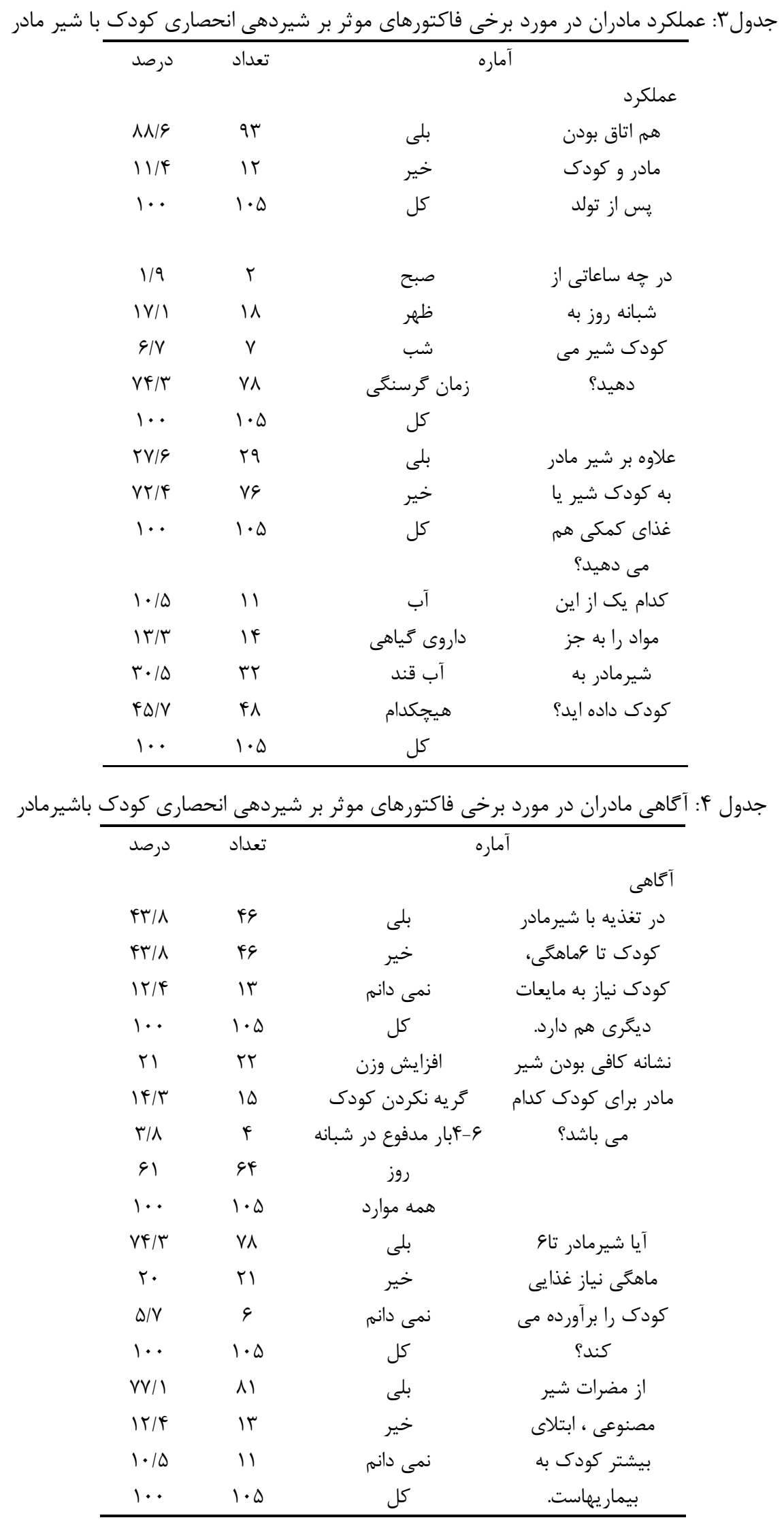




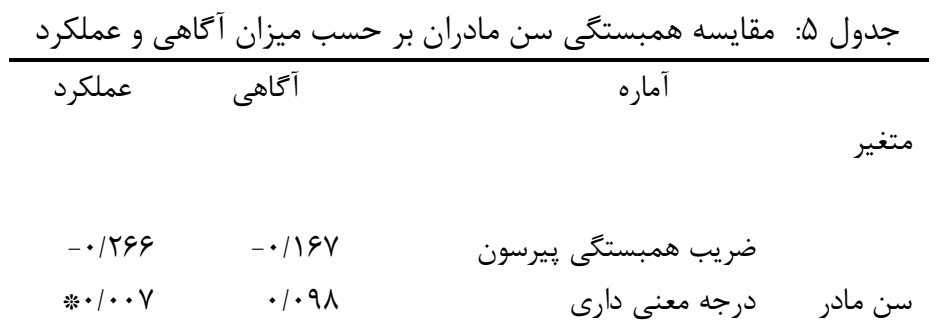

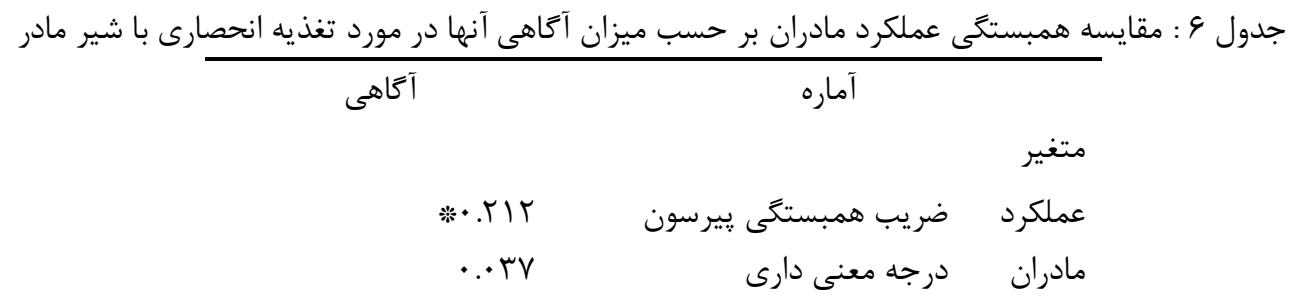

انحصارى با شير مادر داشته اند. اين آزمون همجنين نشان

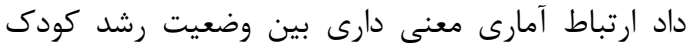
وعملكرد مادر در مورد تغذيه انحصارى با شيرمادر وجود الماري

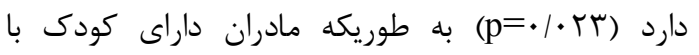

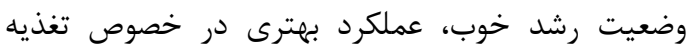

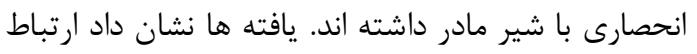
آمارى معنى دارى بين منطقه محل سكونت مادر و ميزان

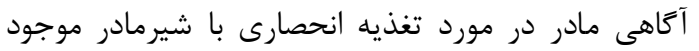

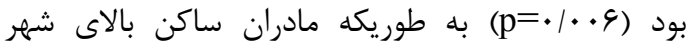

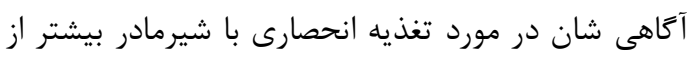

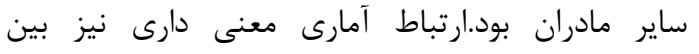
تحصيلات و شغل يدر و عملكرد مادران در مورد تغذيه انحصارى باشير مادر موجود بود، به طوريكه كودكانى كه

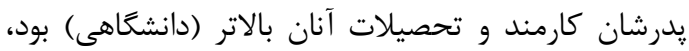
مادرشان عملكرد بهترى در مورد تغذيه انحصارى باشير

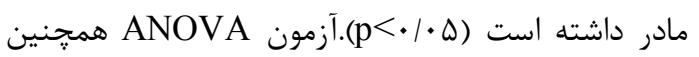

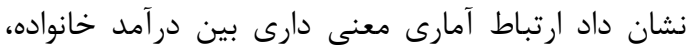

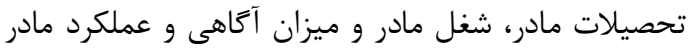

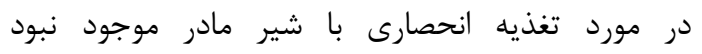
.$(p>\cdot / \cdot \Delta)$
دارد و VA درصد مادران هم اعتقاد داشتند كه در 9 ماهه

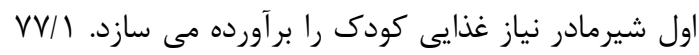

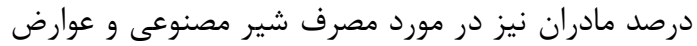
آن براى كودى اطلاع كافى داشتند.

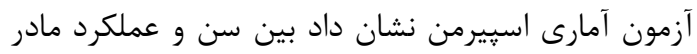

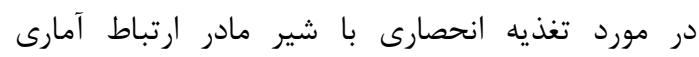

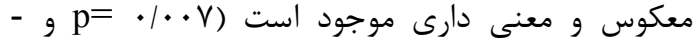

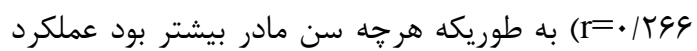
ضعيف ترى نسبت به تغذيه انحصارى با شير مادر وجود

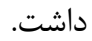
آزمون اسييرمن نشان داد رابطه آمارى معنى دارى بين آكاهى و عملكرد مادران موجود است (

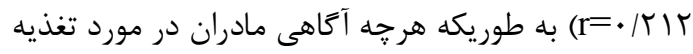
انحصارى با شير مادر بيشتر بود ، عملكرد بهترى در مورد تغذيه انحصارى با شير مادر داشته اند.

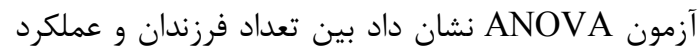

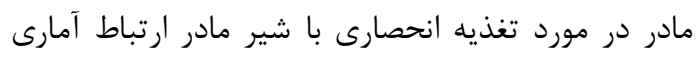

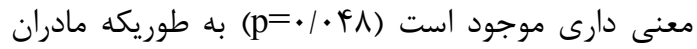
داراى يك فرزند عملكرد بهترى در خورد خصوص تغذيه به بهوريه مادران 
آموزش يدر در مورد اهميت تغذيه با شير مادر و رفع مشكلات و موانع تغذيه با آن، با افزايش ميزان تغذيه بهريه انحصارى با شير مادر در و ماهه اول زندگى كودى همراه

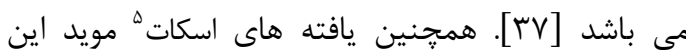
بود كه بين ادامه تغذيه با شير مادر و ميزان آكَاهى، نخرش

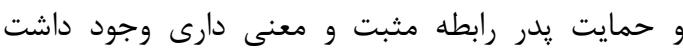

در مطالعه حاضر بين سن مادر و تعداد فرزندان و عملكرد

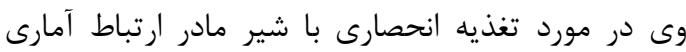

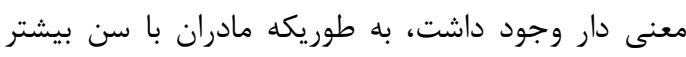
عملكرد ضعيف ترى نسبت به تغذيه انحصارى با شير مادر داشتند كه مى تواند به دليل تعداد فرزندان بيشتر باشد.

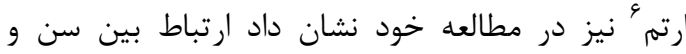
تغذيه انحصارى كودى با شير مادر معنى دار مى باشد

[rq]

نتايج مطالعه حاضر همٍنين نشان داد ارتباط بين تعداد فرزندان (يك فرزند) و عملكرد بهتر مادر در مورد تغذيه انحصارى معنى دار مى باشد. اين نتايج با يافته هاى

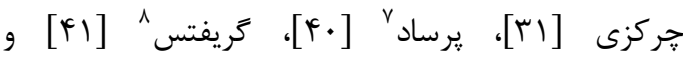

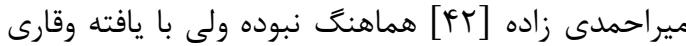

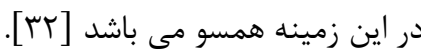
نتايج اين مطالعه نشان داد ارتباط آمارى معنى دمى دارى بـى بين محل سكونت و آكاهى مادران در مورد تغذيه انحصارى باشير مادر وجود داشت، نتايج اين مطالعه نشان داد ماد مورد مادران ساكن در مناطق مرفه شهر اطلاعات بيشترى در

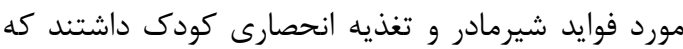
مى تواند به دليل تحصيلات بيشتر آنها و همسرانشان، داشتن فرزند كمتر و برخوردارى بيشتر از امكانات مراكز بهداشتى درمانى (شركت در كلاس هاى آموزشى، مطالعه يمفلت و بروشورهاى اطلاع رسانى در مورد فوايد شيردهى و تغذيه انحصارى براى كودى) باشد. اين نتايج با يافته

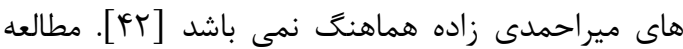

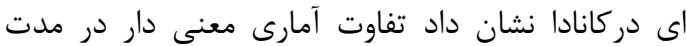
تغذيه انحصارى با شير مادر بين كودكان شهرى و وادى

$5-\mathrm{Scott}$

6 -Ertem

7 -Persad

8 - Griffiths
در اين مطالعه ه.1 مادر شيرخوار 9 تا Fا ماهده كه تحت بوشش مراكز بهداشتى درمانى شهرستان مشهد بودند از نظر ميزان آكاهى و عملكرد در مورد تغذيه انحصارى باني شير مادر مورد بررسى قرار كرفتند. شيوع تغذيه انحصارى با شير مادر در 9 ماهه اول تولد كودى در اين مطالعه

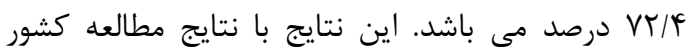

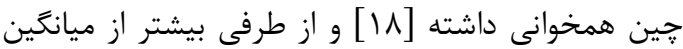

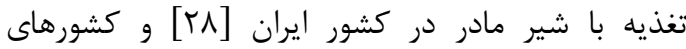

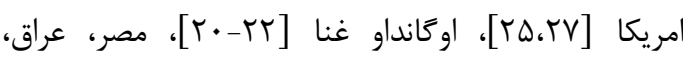

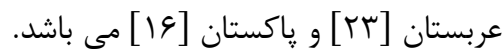

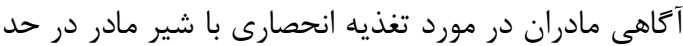

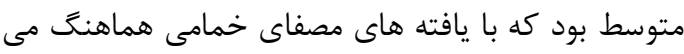

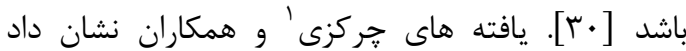

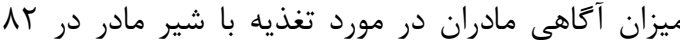

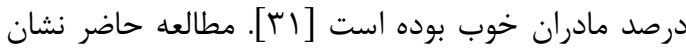
داد عملكرد مادران در زمينه تغذيه انحصارى با شير مادر نيز در حد متوسط مى باشد. طبق نتايج اين مطالعه رابطه آمارى معنى دارى بين تحصيلات بدر كودى (دانشخاهى) و شغل يدر (كارمند) با عملكرد بهتر مادر در زمينه تغذيه تاريه انحصارى كودى با شير مادر وجود داشت كه با يافته هاى بداي

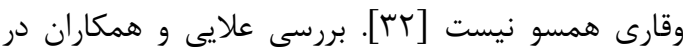

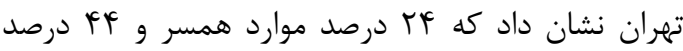
خواهر و مادرخانم و يا همسر وى و در بـ درص درصد موارد ساير افراد فاميل و دوستان و كادر درمانى مشوق شيردها فهى

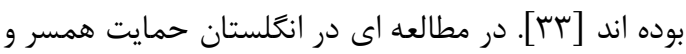

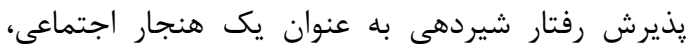
حمايت از طرف دوستان از عوامل مههم براى شروع و تداوم

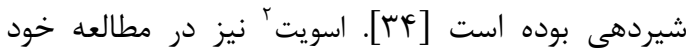

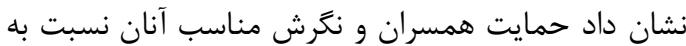
تغذيه با شيرمادر در تداوم شيردهى نوزادان نارس موثري

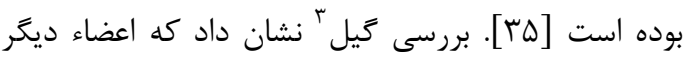

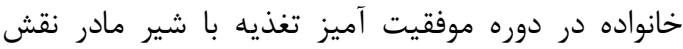

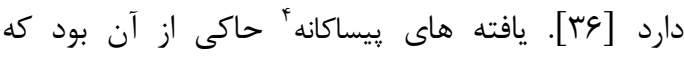

1 -Cherkzi

2 -Sweet

3 -Gill

4 -Pisacane 
روستايى وجود دارد [بא]]. مطالعه حاضر نشان داد رابطه آمارى معنى دارى بين سطح سواد و شغل مادر با تغذيه

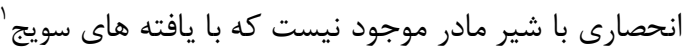

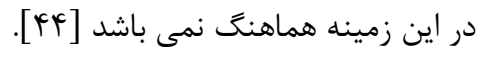

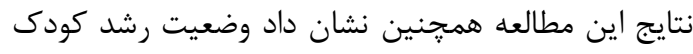
با عملكرد مادر در زمينه تغذيه انحصارى مرتبط مى بـ باشد،

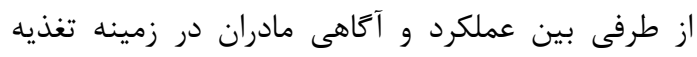

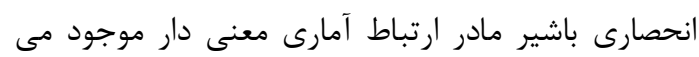

تغذيه انحصارى كودى با شير مادر بيشتر از ميانكين

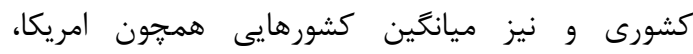
كشورهاى افريقايى مثل غنا و اوكاندا و نيز كشورهاى عضى عضو هماني

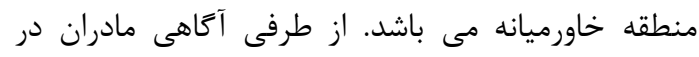

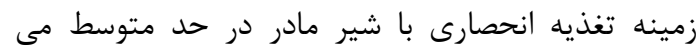

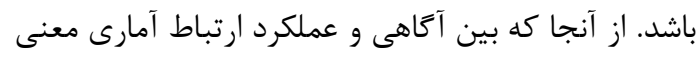

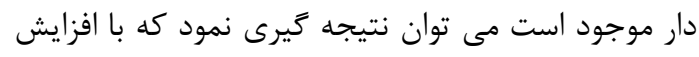

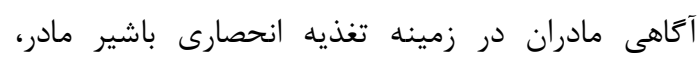

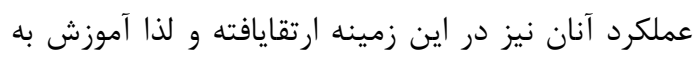

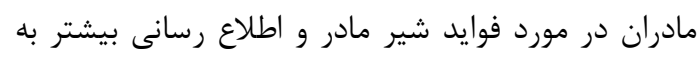

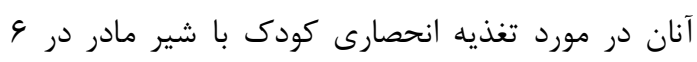

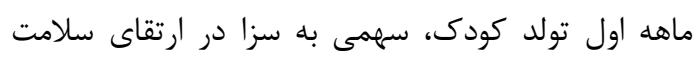
كودكان جامعه خواهد داشت.

تشكر و قدردانى جامعان

از همكارى و مشاوره ارزشمند معاونت فنى مركز بهداشت ودردانى

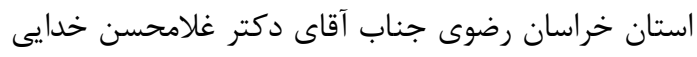

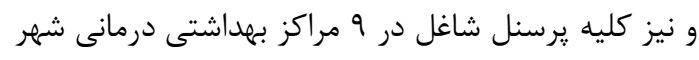

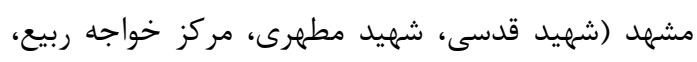
دانش آموز، آب و برق، شهيد صفارى، التيمور، جههارده

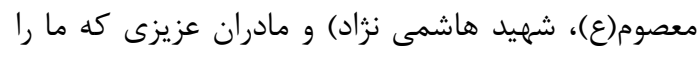

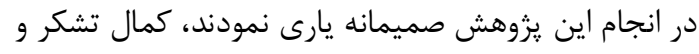
قدردانى را داريم. 


\section{References}

1. Baby-Friendly Hospital Initiative Revised, Updated and Expanded for Integrated Care 2009 WHO Press, World Health Organization, 20 Avenue Appia, 1211 Geneva 27, Switzerland

http://www.unicef.org/nutrition/files/BFHI,(20 $09 \_$s3.1\&2).

2. Horta BL, Bahl R, Martines JC, Victora CG: Evidence on the long-term effects of breastfeeding.Systematic reviews and metaanalysis. Geneva: World Health Organization 2007.

3. Gartner LM, Morton J, Lawrence RA, Naylor AJ, O'Hare D, Schanler RJ, Eidelman AI,American Academy of Pediatrics Section on Breastfeeding: Breastfeeding and the use of human milk. Pediatrics 2005, 115: 496-506.

4. Walker A. Breast milk as the gold standard for protective nutrients. J Pediatr. 2010; 156(2Suppl):S3-7. Review.

5. Imani M, Mohamadi M, Rakhshani F. [Prevalence and factors associated with exclusive breastfeeding in Zahedan (Persian)]. Faiz 2003;26(7):26-33

6. Abedzadeh M, Saberi F, Sadat Z.[Quality of nutrition and factors related to it in $4 / 5$ month old babies of Kashan (Persian)]. Faiz 2005;3: 59-64.

7. Jones G, Steketee RW, Black RE, Bhutta ZA, Morris SS:How many child deaths can we prevent this year? Lancet 2003, 362:65-71.

8. WHO Collaborative Study Team on the Role of Breastfeeding on the Prevention of Infant Mortality: Effect of breastfeeding on infant and child mortality due to infectious diseases in less developed countries: a pooled analysis. Lancet2000, 355(9202):451-455.

9. Scott JA, Landers MC, Hughes RM, Binns $\mathrm{CW}$ : Factors associated with breastfeeding at discharge and duration of breastfeeding. J Paediatr Child Health 2001, 37(3):254-261.

10. WHO: The optimal duration of exclusive breastfeeding.Geneva 2001.

11. Breastfeeding trends and updated national health objectives for exclusive breastfeeding United States, birth years 2000-2004. MMWR Morb Mortal Wkly Rep 2007,56(30):760-763. 12. Innis SM: Perinatal biochemistry and physiology of longchain polyunsaturated fatty acids. J Pediatr 2003, 143(4Suppl):S1-8.
13. WHO: Report of the expert consultation on the optimal duration of exclusive breastfeeding World Health Organization; 2001.

14. American Academy of Pediatrics (AAP). Work Group on Breastfeeding. Breastfeeding and the use of human milk.Pediatrics. 1997;100(6):1035-1039.

15. World Health Organization. WHO Expert committee report. Geneva, WHO; 2001.

16. Kramer MS, Kakuma R. The optimal duration of exclusive breastfeeding: a systematic review. Geneva,World Health Organization, 2001

(WHO/NHD/01.08; WHO/FCH/01.23).

17. Global Strategy on Infant and Young Child Feeding $55^{\text {th }}$ World Health Assembly. Geneva 2003:

http://www.who.int/nutrition/publications/gs i nfant_feeding _text_eng, (7 May 2007).

18. Xu F, Qiu L, Binns CW, Liu X. Breastfeeding in China: a review. Int Breastfeed J. 2009, 16:4-6.

19. United Nations Children's Fund (UNICEF): Progress for Children: A Child Survival Report Card 2004 [http://www.unicef.org/publications/files/2965 2L01Eng.pd f],( September 2004).

20. Ssenyonga $R$, Muwonge R, Nankya I. Towards a better understanding of exclusive breastfeeding in the era of HIV/AIDS: a study of prevalence and factors associated with exclusive breastfeeding from birth, in Rakai,Uganda. J Trop Pediatr 2004 ;50(6):34853.

21. Aidam BA, Pérez-Escamilla R, Lartey A, Aidam J. Factors associated with exclusive breastfeeding in Accra, Ghana. Eur J Clin Nutr 2005; 59(6): 789-96.

22. Ogbeide DO, Siddiqui S, Al Khalifa IM, Karim A. Breast feeding in a Saudi Arabian community. Profile of parents and influencing factors. Saudi Med J 2004; 25(5): 580-4.

23. The state of the world's children. 2008, [Child survival] New York: UNICEF; 2007.

24. Santo LC, de Oliveira LD, Giugliani ER. Factors associated with low incidence of exclusive breastfeeding for the first 6 months. Birth 2007;34(3):212-9.

25. US. Department of Health and Human Services. Chapter 16. Maternal, Infant, and Child Health. Healthy People 2010 ( $2^{\text {nd }}$ Ed.): With Understanding and Improving Health and Objectives for Improving Health. Vol 
26.Washington, DC: US. Governmental Printing Office; 2000.

27. Ryan AS, Zhou W, Acosta A. Breastfeeding continues to increase into the new millennium. Pediatrics.2002;110(6):11031109.

28. Kramer MS, Kakuma R. The Ministry of Health IR of Iran, Breastfeeding office: http:/www .bfps.ir/ (i5emlr45w1kdeg45tov0ysem)/Persian/Home.a spx, (2009).

29. Venancio SI, Monteiro CA. Individual and contextual determinants of exclusive breastfeeding in S?o Paulo,Brazil: a multilevel analysis. Public Health Nutr 2006; 9(1): 40-6.

30. Mosaffa H. Survey of the knowledge and attitude of mothers during one year after delivery about breast-feeding.Journal of Guilan University of Medical Sciences 2004; 13(51): 23-31.

31. 31.Cherkzi A,Miraeiz Z,Razaghnejad A,Shahnazi H,Hasanzadeh A,Badeleh MT.Breastfeeding status at the end of two years and Factors affecting by the structure of the BASNEF in Esfahan City. Journal of Health Systems Research 2010, 6 (2):0-0.

32. Veghari GH , Rahmati R . Breastfeeding Status and Some of its Related Factors in the Golestan Province. IJN. 2011; 24 () :8-18.

33. Alaie N, Faghihzadeh S. Relationship of Mother Factors with Mothers' Attitude about Breast Feeding. Daneshvar Medicine AprilMay 2008; 15(74): 31-40.

34.Bertini G, Perugi S, Dani C, Pezzati M, Tronchin M, Rubaltelli FF. Maternal education and the incidence and duration of breast feeding: a prospective study $\mathrm{J}$ Pediatr Gastroenterol Nutr 2003; 37(4): 447-52.

35. Sweet L, Darbyshire P. Fathers and breast feeding very-low-birthweight preterm babies Midwifery 2009; 25(5):540-53.
36. Gill SL, Reifsnider E, Lucke JF. Effects of support on the initiation and duration of breastfeeding. West $J$ Nurs Res. 2007 Oct;29(6):708-23.

37. Pisacane A, Continisio GI, Aldinucci M, D'Amora S, Continisio P. A controlled trial of the father's role in breastfeeding promotion. Pediatrics. 2005 Oct;116(4):e494-8.

38. Scott JA, Binns CW, Oddy WH, Graham KI. Predictors of breastfeeding duration: evidence from a cohort study. Pediatrics. 2006;117(4):e646.

39. Ertem IO, Votto N, Leventhal JM. The timing and predictors of the early termination of breastfeeding. Pediatrics. 2001 Mar;107(3):543-8.

40. Persad MD, Mensinger JL. Maternal breastfeeding attitudes: association with breastfeeding intent and sociodemographics among urban primiparas $\mathrm{J}$ Community Health 2008; 33(2): 53-60.

41.Griffiths LJ, Tate AR, Dezateux C. The contribution of parental and community ethnicity to breastfeeding practices: evidence from the Millennium Cohort Study Int J Epidemiol 2005; 34(6): 1378-86.

42. Mirahmadizadeh A, Zare P, Moradi F, Sayadi M, Hesami E, Moghadami M. Exclusive breast-feeding weaning pattern and its determinant factors in Fars province in 2010.. 3. 2012; 19 () :11-22.

$\varepsilon r$. Duration of Exclusive Breastfeeding in Canada: Key Statistics and Graphics (20072008). http://www.hesc. gc.ca/fnan/surveill/nutrition/commun/prenatal/ duration-dureeeng.php (Access at 4th Aug 2011).

44. Savage King, F. Helping breast fed mothers. Translated by Dehghani P. IUMS publications, Tehran. 1999.p 44. 
Original Article

\title{
Maternal Knowledge and practice in Mashhad City about Breast- feeding in first 6 -month of Infant's life
}

\author{
Kiani $M A^{1}$, Khakshour $A^{2}$, Vakili $R^{3}$, Saeedi $M^{1}$ * \\ ${ }^{1}$ Assistant professor of Pediatrics Gastroenterology ,Neonatal Research Center, Faculty of Medicine, Mashhad \\ University of Medical Sciences, Mashhad, Iran. \\ ${ }^{2}$ Assistant Professor of Pediatric, North Khorasan University of Medical Sciences, Bojnurd, Iran. \\ ${ }^{3}$ professor of Pediatric Endocrinologist, Endocrine Research Center, Faculty of Medicine, Mashhad University \\ of Medical Sciences, Mashhad, Iran.
}

*Corresponding Author: Students Research Committee, Faculty of Medicine, Mashhad University of Medical Sciences, Mashhad, Iran. Email:

Masumeh_Saeedi@yahoo.com

Submitted:15 Apr 2013

Revised:3 June 2013

Accepted: 11June 2013

\section{Abstract}

Background \& Objectives: Breastfeeding is an important principle in pediatric health. It decreases their mortality and protect them fromm diseases in the first 6-month of life. This study aimed to determined Maternal Knowledge and practice in Mashhad City about Breast-feeding in first 6 -month of Infant's life.

Material and Methods: This Analytic study was conducted on 105 mothers who had a child between 6 to 12 months, and selected by the cluster sampling and simple random, completed the Knowledge and Practic questionnaire who was made by researchers. Information were analyzed by descriptiveanalytical test (ANOWA,T-test,corelation) in spss software in version11.5.

Results: This findings showed that $72 / 4 \%$ of infants have had exclusive until end of the first 6-month.

breast-feeding. Average of maternal knowledge about exclusive breast-feeding was 19/818+4/545 of total score 28 and average of maternal practice was 7/106+2/338 of total score 12. Status of growth infants at $4 / 8 \%$ was very good and in $42 / 9 \%$ was good. There was a significant relationship between maternal practice about Breast-feeding and fathers' education, number of children, status of growth $(p<0.05)$. There was a significant relationship between maternal knowledge about Breast-feeding and area who lived there $(p<0.05)$ and also there was a direct and positive correlation between maternal knowledg and practice $(p=0.000$, $r=0.212)$. There was a significant relationship and reverse between maternal practice and age of mothers $(p=0.007, r=-$ $0.266)$.

Conclusion: Maternal Knowledge and practice about breastfeeding infants is moderate. Planning is essential to target groups to promote breastfeeding in the first 6- month of infant's life.

Keywords: Knowledge, Practice ,Exclusive,Infant. 